\title{
Untangling normal aging from disease-related brain atrophy in MS
}

Tim Sinnecker, MD and Jens Wuerfel, MD

Neurol Neuroimmunol Neuroinflamm 2019;6:e617. doi:10.1212/NXI.0000000000000617

An accelerated brain atrophy rate is highly prevalent already in early MS and is known to correlate with cognitive and physical disability. ${ }^{1}$ Brain volume loss has therefore emerged as an important outcome measure in clinical MS studies. Nonetheless, in our daily clinical routine, quantitative brain volume measurements have not been widely implemented to monitor disease activity or treatment responses of individual patients with MS. To do this, there are some biological and technical limitations to be taken into consideration: ${ }^{1}$

Brain volume changes quantified by MRI do not necessarily reflect brain parenchymal tissue loss. Indeed, brain volume changes may result from the current physiologic state, e.g., variations in hydration or time point in the circadian rhythm. Also, the degree of inflammatory edema may significantly influence the measurement of brain volumes. On top of that, current techniques to measure brain volumes and brain volumetric changes using MRI are not free of errors, which often exceed $0.1 \%-0.2 \%$ (median) for longitudinal techniques and $1 \%$ (median) for crosssectional approaches. ${ }^{1}$

True brain atrophy reflects tissue degradation in normal aging or pathologic circumstances caused by neurodegenerative processes, which include loss of neurons, glial cells, and axons. The contributing factors may overlap and accumulate ${ }^{2}$ being of particular importance in patients with progressive MS. Untangling age- and disease-specific effects of brain atrophy by discerning novel biomarkers for MS-related neurodegeneration would thus be an important step toward clinical application of volumetric brain imaging. ${ }^{2}$

In this issue of Neurology: Neuroimmunology \& Neuroinflammation, Azevedo et al. ${ }^{3}$ applied mixedeffects models to a large MS cohort and 2 smaller cohorts of healthy controls (HCs). In a cohort spanning several decades, the authors observed that during aging, the relative share of MS-specific brain volume change decreased, whereas the proportion of age-related brain volume change increased. In more detail, the rate of disease-attributed brain volume loss decreased from $-0.38 \%$ / $y$ by age 30 years to $-0.12 \% / y$ when participants reached age 60 years. At the same time, the rate of age-attributed brain volume changes accelerated from $0.01 \% / y$ to $-0.31 \% / y$.

The present study supports previous findings ${ }^{4}$ that brain volume loss in MS is influenced by multiple factors and that the currently applied disease-modifying therapies may not have a direct impact on it. $^{2}$

The second key finding of the study by Azevedo et al. is that the deceleration of MS-specific brain volume change and the acceleration of age-related brain volume change during aging were more pronounced in the thalamus compared with the whole brain, however not detectable in the putamen and caudate nuclei.
Correspondence

Dr. Sinnecker

Tim.Sinnecker@usb.ch

\section{RELATED ARTICLE}

Contribution of normal aging to brain atrophy in MS

Page e616

Other studies have investigated disease- and region-specific brain volume changes in MS. The same research group reported that thalamic volume loss was consistent not only throughout the

From the Departments of Medicine (T.S.), Neurologic Clinic and Policlinic, University Hospital Basel and University of Basel; qbig (T.S., J.W.), Department of Medicine and Biomedical Engineering, University Hospital Basel and University of Basel; Medical Image Analysis Center Basel AG (T.S., J.W.); and Translational Imaging in Neurology [ThINK] Basel (T.S.), Department of Medicine and Biomedical Engineering, University Hospital Basel and University of Basel, Switzerland. 
MS disease duration, but also in radiologically isolated syndrome patients. However, the authors noted that a larger group of HCs was needed to draw final conclusions. ${ }^{5} \mathrm{~A}$ smaller study by Bishop et al. ${ }^{6}$ also observed higher volume changes in both younger and older patients with MS vs HCs within the putamen and the thalamus, but differences in caudate volume loss did not reach statistical significance. Finally, a large retrospective MRI study by Ghione et al. ${ }^{7}$ observed accelerated increase of the lateral ventricle volumes predominantly within HCs, but not in patients with MS.

If the concept of disease- and region-specific brain atrophy in MS holds true, it would indeed allow for a better untangling of age- and disease-specific brain atrophy in MS. Surrogate brain areas could be defined that are more susceptible to MSspecific brain atrophy than atrophy caused by other mechanisms. Although the study by Azevedo et al. provides novel insights into this field, some open research questions still have to be faced.

It is still not well understood whether - and to what extent-MS disease activity and disease course modulate the relationship between age- and MS-specific brain atrophy. The study by Azevedo et al. cannot shed light on this because their MS cohort is characterized by an overall low disease activity (mean Expanded Disability Status Scale score 1.8 after a mean disease duration of 9.2 years), only $7.3 \%$ of all patients had secondary progressive MS, and none had primary progressive MS.

On the other hand, it would be interesting to identify the effects of comorbidities and genetic or lifestyle factors such as diet, smoking, and alcohol consumption on the share of MS-specific brain atrophy in elderly patients, as all of these factors were shown to alter brain atrophy during aging. Information on comorbidities was not reported in the study of Azevedo et al.

Furthermore, it is worthwhile to study the discriminative abilities of spinal cord volume loss to distinguish relapsing from progressive MS subgroups or to differentiate between MS-specific and age-related CNS atrophy. ${ }^{9}$

From a methodological and technical point of view, a limitation of this study is that 2 different and relatively small HC cohorts with shorter follow-up and in part different sequence parameters in comparison to the MS cohort were included. In addition, one might hypothesize that the study lacks power to untangle age- vs MS-specific brain volume changes in the putamen and caudate nuclei, as the measurement error for volume changes within these small subcortical structures might be higher than for whole-brain volume changes. ${ }^{10}$

In summary, the study by Azevedo et al. improves our understanding on the complex interaction of age- and diseasespecific brain atrophy in MS, as so far only limited information on this issue is available in the literature. Brain volume loss remains a complex phenomenon that is modulated by various factors and not merely the reflection of a single condition as MS.

\section{Study funding}

No targeted funding reported.

\section{Disclosure}

T. Sinnecker received travel support from Actelion and Roche and speaker fees from Biogen and is part-time employee of the Medical Image Analysis Center Basel. J. Wuerfel is CEO of the Medical Image Analysis Center Basel. He served on scientific advisory boards for Actelion, Biogen, Genzyme-Sanofi, Idorsia, Novartis, and Roche. $\mathrm{He}$ is or was supported by grants of the EU (Horizon 2020), German Federal Ministries of Education and Research (BMBF), and of Economic Affairs and Energy (BMWI). Go to Neurology.org/NN for full disclosures.

\section{References}

1. Sinnecker T, Granziera C, Wuerfel J, Schlaeger R. Future brain and spinal cord volumetric imaging in the clinic for monitoring treatment response in MS. Curr Treat Options Neurol 2018;20:17.

2. Geraldes R, Esiri MM, DeLuca GC, Palace J. Age-related small vessel disease: a potential contributor to neurodegeneration in multiple sclerosis. Brain Pathol 2017;27: 707-722.

3. Azevedo CJ, Cen SY, Jaberzadeh A, Zheng L, Hauser SL, Pelletier D. Contribution of normal aging to brain atrophy in MS. Neurol Neuroimmunol Neuroinflamm 2019;6: e616. doi: 10.1212/NXI.0000000000000616.

4. Opfer R, Ostwaldt AC, Sormani MP, et al. Estimates of age-dependent cutoffs for pathological brain volume loss using SIENA/FSL-a longitudinal brain volumetry study in healthy adults. Neurobiol Aging 2018;65:1-6.

5. Azevedo CJ, Cen SY, Khadka S, et al. Thalamic atrophy in multiple sclerosis: a magnetic resonance imaging marker of neurodegeneration throughout disease. Ann Neurol 2018;83:223-234

6. Bishop CA, Newbould RD, Lee JS, et al. Analysis of ageing-associated grey matter volume in patients with multiple sclerosis shows excess atrophy in subcortical regions. Neuroimage Clin 2016;13:9-15.

7. Ghione E, Bergsland N, Dwyer MG, et al. Aging and brain atrophy in multiple sclerosis. J Neuroimaging 2019;29:527-535.

8. Enzinger C, Fazekas F, Matthews PM, et al. Risk factors for progression of brain atrophy in aging: six-year follow-up of normal subjects. Neurology 2005;64: 1704-1711.

9. Tsagkas C, Magon S, Gaetano L, et al. Preferential spinal cord volume loss in primary progressive multiple sclerosis. Mult Scler 2019;25:947-957.

10. Meijerman A, Amiri H, Steenwijk MD, et al. Reproducibility of deep gray matter atrophy rate measurement in a large multicenter dataset. Am J Neuroradiol 2018;39: $46-53$. 


\section{Neurology $^{\odot}$ \\ Neuroimmunology \& Neuroinflammation}

Untangling normal aging from disease-related brain atrophy in MS

Tim Sinnecker and Jens Wuerfel

Neurol Neuroimmunol Neuroinflamm 2019;6;

DOI 10.1212/NXI.0000000000000617

This information is current as of September 25, 2019

\section{Updated Information \& Services}

References

Subspecialty Collections

Permissions \& Licensing

Reprints including high resolution figures, can be found at:

http://nn.neurology.org/content/6/6/e617.full.html

This article cites 10 articles, 1 of which you can access for free at: http://nn.neurology.org/content/6/6/e617.full.html\#\#ref-list-1

This article, along with others on similar topics, appears in the following collection(s):

All Demyelinating disease (CNS)

http://nn.neurology.org//cgi/collection/all_demyelinating_disease_cns Cerebrospinal Fluid

http://nn.neurology.org//cgi/collection/cerebrospinal_fluid

MRI

http://nn.neurology.org//cgi/collection/mri

Multiple sclerosis

http://nn.neurology.org//cgi/collection/multiple_sclerosis

Information about reproducing this article in parts (figures,tables) or in its entirety can be found online at:

http://nn.neurology.org/misc/about.xhtml\#permissions

Information about ordering reprints can be found online:

http://nn.neurology.org/misc/addir.xhtml\#reprintsus

Neurol Neuroimmunol Neuroinflamm is an official journal of the American Academy of Neurology.

Published since April 2014, it is an open-access, online-only, continuous publication journal. Copyright

Copyright () 2019 The Author(s). Published by Wolters Kluwer Health, Inc. on behalf of the American

Academy of Neurology.. All rights reserved. Online ISSN: 2332-7812.

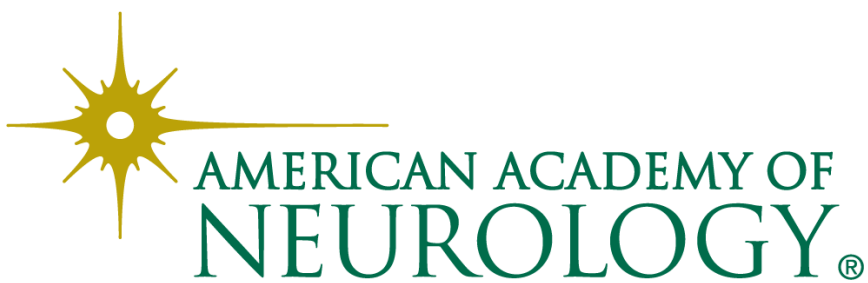

